\title{
Torque teno virus among dialysis and renal-transplant patients
}

\author{
Angélica Yukari Takemoto ${ }^{1}$, Patrícia Okubo ${ }^{1}$, Patricia Keiko Saito ${ }^{2}$, \\ Roger Haruki Yamakawa ${ }^{2}$, Maria Angélica Ehara Watanabe ${ }^{3}$, \\ Waldir Veríssimo da Silva Junior ${ }^{4}$, Sueli Donizete Borelli ${ }^{5}$, João Bedendo ${ }^{6}$ \\ ${ }^{1}$ Departamento de Enfermagem, Universidade Estadual de Maringá, Maringá, PR, Brazil. \\ ${ }^{2}$ Departamento de Ciências Básicas da Saúde, Universidade Estadual de Maringá, Maringá, PR, Brazil. \\ ${ }^{3}$ Departamento de Patologia, Universidade Estadual de Londrina, Londrina, PR, Brazil. \\ ${ }^{4}$ Departamento de Estatística, Universidade Estadual de Maringá, Maringá, PR, Brazil. \\ ${ }^{5}$ Departamento de Ciências Básicas, Universidade Estadual de Maringá, Maringá, PR, Brazil. \\ ${ }^{6}$ Departamento de Enfermagem, Universidade Estadual de Maringá, Maringá, PR, Brazil.
}

Submitted: November 12, 2013; Approved: June 6, 2014.

\begin{abstract}
Patients who undergo dialysis treatment or a renal transplant have a high risk of blood-borne viral infections, including the Torque teno virus (TTV). This study identified the presence of TTV and its genome groups in blood samples from 118 patients in dialysis and 50 renal-transplant recipients. The research was conducted in a hospital in the city of Maringá, state of Paraná. The viral DNA, obtained from whole blood, was identified by using two nested Polymerase Chain Reactions (PCR). The frequencies of TTV were $17 \%$ and $36 \%$ in dialysis patients using the methodology proposed by Nishizawa et al. (1997) and Devalle and Niel (2004), respectively, and 10\% and 54\% among renal-transplant patients. There was no statistically significant association between the frequency of the pathogen and the variables: gender, time in dialysis, time since transplant, blood transfusions, and the concomitant presence of hepatitis $\mathrm{B}$, for either the dialysis patients or the renal-transplant recipients. Among dialysis patients and renal-transplant recipients, genogroup 5 was predominant $(48 \%$ and $66 \%$ respectively), followed by genogroup 4 (37\% and $48 \%$ ) and genogroup 1 (23\% and $25 \%)$. Genogroup 2 was present in both groups of patients. Some patients had several genogroups, but $46 \%$ of the dialysis patients and $51 \%$ of the renal-transplant recipients had only a single genogroup. This study showed a high prevalence of TTV in dialysis patients and renal-transplant recipients.
\end{abstract}

Key words: torque teno virus, renal dialysis, kidney transplant, infection.

\section{Introduction}

Patients with chronic renal failure are at risk of acquiring microorganisms and developing infections. The most common etiologic agents are bacteria and viruses, such as the Torque teno virus (TTV). TTV was discovered in 1997 in the bloodstream of Japanese patients with posttransfusion hepatitis, and its name is derived from the initials of the first patient diagnosed. The initials of the name can also indicate a transfusion-transmitted virus (Nishizawa et al., 1997; Okamoto et al., 1998; Bendinelli et al., 2001), although transfusions are not the most frequent means of transmission (Watanabe et al., 2005). Subsequently, this virus was named Torque Teno, keeping the initials TTV (Biagini et al., 2004).

Studies indicate that the estimated frequency of the virus can vary with the genomic region tested, as well as with the geographic location studied (Bendinelli et al., 2001). The modes of transmission are incompletely understood and are widely discussed in the literature. Parenteral transmission is an important propagation route (Nishizawa et al., 1997), but the virus can also be transmitted by blood transfusion (Oza et al., 2004) and by blood derivatives (Barril et al., 2004). Other routes have been identified, in-

Send correspondence to A.Y. Takemoto. Departamento de Enfermagem, Universidade Estadual de Maringá, Maringá , PR, Brazil. E-mail: angelica.takemoto@hotmail.com. 
cluding sexual (Krekulova et al., 2001; Saláková et al., 2009), vertical (Iso et al., 2001; Bagaglio et al., 2002), and fecal-oral (Leary et al., 1999; Griffin et al., 2008).

TTV is present worldwide (Prescott and Simmonds, 1998; Amarante et al., 2007), and is organized in five large phylogenetic groups (Peng et al., 2002). This high genetic diversity implies that some genotypes may have a pathogenic potential (Saláková et al., 2009), but their clinical significance is unknown (Bendinelli et al., 2001). The epidemiology of TTV is little studied, resulting in limited knowledge about the pathogenesis of this viral particle.

A patient's history of multiple blood transfusions is associated with the acquisition of TTV. Lowered immunity can increase the probability of developing a viremia (Yokosuka et al., 2000; Saláková et al., 2004). Although the effects of these factors require clarification, the diagnosis of TTV continues to be difficult because the antibody corresponding to the infection cannot be detected (Campo et al., 2000).

Considering the risk of a TTV infection in patients undergoing renal therapy, and also the need for monitoring to aid in developing measures to control or prevent the transmission of this infectious agent, this study had the objectives of identifying the presence of TTV and its genomic groups in blood samples from patients undergoing dialysis and renal transplant treatment, and evaluating the association between TTV frequency and several variables including gender, age, time in dialysis, time since transplant, blood transfusions, and the concomitant presence of the hepatitis B virus.

\section{Materials and Methods}

A quantitative study with a descriptive exploratory approach was carried out in the dialysis unit of a medium-sized hospital in the city of Maringá, Paraná. During the period of data collection, from January to June 2011, the unit registered 153 patients in dialysis and 60 renal-transplant patients. The patients who underwent renal transplants formed a distinct group from the dialysis patients, since they were not on dialysis. These individuals were recruited during routine clinical consultation. The study sample was composed of 118 dialysis and 50 renal-transplant patients, aged 18 years or more. Individuals who showed difficulty in understanding or clinical instability during the data collection were excluded, as were patients who declined to participate in the study.

We analyzed the frequency of TTV with respect to its association with gender, age, time in dialysis, time since transplant, number of blood transfusions and the presence of hepatitis B. For this last variable, we used information from medical records.

Peripheral blood samples $(10 \mathrm{~mL})$ was collected by venipuncture, in sterilized vacuum tubes with an anticoagulant. For DNA extraction the PureLink ${ }^{\circledR}$ genomic DNA (Invitrogen) kit was used, following the manufacturer's recommendations. The genomic DNA was detected by electrophoresis at $100 \mathrm{~V}$ for $20 \mathrm{~min}$, using $1.5 \%$ agarose gel, staining with ethidium bromide and observation in ultraviolet light.

The viremia in the peripheral blood was identified through the nested PCR technique, using the primers RD037 (5'-GCAGCAGCATATGGATATGT-3'), RD038 (5'-TGACTGTGCTAAGGCCTCTA-3'), RD051 (5'-CATACACATGAATGCCAGGC-3') and RD052 (5'-GTACTTCTTGCTGGTGAAAT-3') (Nishizawa et al., 1997). The final product indicating the presence of TTV was an amplified fragment of $197 \mathrm{bp}$. Both amplification reactions were carried out under the same conditions, using a final volume of $25 \mu \mathrm{L}$ and the following reagents: $0.75 \mu \mathrm{L}$ $\mathrm{MgCl}_{2}(50 \mathrm{mM}) ; 2.0 \mu \mathrm{L}$ of dNTP $(1.25 \mathrm{mM}) ; 1.0 \mu \mathrm{L}$ of sense primer $(2.5 \mu \mathrm{M}) ; 1.0 \mu \mathrm{L}$ of anti-sense primer $(2.5 \mu \mathrm{M}) ; 12.75 \mu \mathrm{L}$ of sterile Milli-Q $\mathrm{H}_{2} \mathrm{O} ; 2.5 \mu \mathrm{L}$ of taq polymerase (1.25 U/reaction); and $2.5 \mu \mathrm{L}$ of genomic DNA sample and/or PCR 1 product $(0.1 \mu \mathrm{g} / \mu \mathrm{L})$.

The first and second rounds of amplification used an initial denaturing temperature at $94^{\circ} \mathrm{C}$ for $10 \mathrm{~min}$, followed by 35 cycles of $30 \mathrm{~s}$ at $94^{\circ} \mathrm{C}$ to denature the double strand of DNA, $30 \mathrm{~s}$ at $53{ }^{\circ} \mathrm{C}$ for annealing, and $45 \mathrm{~s}$ at $72{ }^{\circ} \mathrm{C}$ for extension, with a final extension of $10 \mathrm{~min}$ at $72{ }^{\circ} \mathrm{C}$. The amplified product was observed by electrophoresis in $2 \%$ agarose gel at $90 \mathrm{~V}$ for $35 \mathrm{~min}$, and staining with ethidium bromide.

The genomic groups were detected using genomic DNA with 3 universal primers as proposed by Devalle and Niel (2004). The nested PCR was carried out with the amplified product, using 5 primers for the identification of genomic groups 1 to 5 (Devalle and Niel, 2004). Summarizing, the amplification reaction of the first round was carried out with a final volume of $25 \mu \mathrm{L}$, composed of $2.5 \mu \mathrm{L}$ of DNA, $0.2 \mathrm{mM}$ dNTP, $3 \mathrm{mM} \mathrm{MgCl}, 0.2 \mu \mathrm{M}$ of each sense and anti-sense primer, and $0.75 \mathrm{U}$ of platinum TaqDNA polymerase. After DNA initial denaturing for $1 \mathrm{~min}$ and $30 \mathrm{~s}$ at $94^{\circ} \mathrm{C}$, the amplification was carried out in 35 cycles at $94{ }^{\circ} \mathrm{C}$ for $30 \mathrm{~s}, 59^{\circ} \mathrm{C}$ for $30 \mathrm{~s}$ and $72{ }^{\circ} \mathrm{C}$ for $3 \min 30 \mathrm{~s}$, followed by final elongation for $10 \mathrm{~min}$ at $72^{\circ} \mathrm{C}$. The second round of PCR was carried out with $1 \mu \mathrm{L}$ of the product of the first PCR and $0.5 \mathrm{U}$ of TaqDNA polymerase. The initial DNA denaturing step was 3 min at $94{ }^{\circ} \mathrm{C}$, followed by amplification for 30 cycles at $94^{\circ} \mathrm{C}$ for $30 \mathrm{~s}, 59^{\circ} \mathrm{C}$ for $30 \mathrm{~s}$ and $72^{\circ} \mathrm{C}$ for $1 \mathrm{~min} 15 \mathrm{~s}$, with a final elongation for $7 \mathrm{~min}$ at $72^{\circ} \mathrm{C}$. The amplified product was observed in electrophoresis in $2 \%$ agarose gel stained with ethidium bromide and revealed in ultraviolet light. This PCR reaction for the determination of genomic groups was carried out with all 118 samples, including those which showed negative results for the presence of viral DNA. 


\section{Statistical analysis}

The data were recorded in an Excel ${ }^{\circledR}$ spreadsheet. The software Statistica 7.1 was used to obtain the descriptive analysis. In the comparative analyses, Student's t-test and Fischer's exact test were used, with a confidence interval of $95 \%(p<0.05)$.

\section{Ethical aspects}

This study was conducted with the permission of the Research Ethics Committee of the State University of Maringá, report no. 562/2010, and abided by all ethical principles established by Resolution 196, dated October 10, 1996, of the National Health Council. All individuals signed the free and informed consent form.

\section{Results}

The dialysis patients were mostly males (66/118; $55 \%$ ) with a mean age of 53.8 years (SD, standard deviation 16.0). The mean time in dialysis was 41.8 months (SD 44.7 months). Hepatitis B was present in only 4 dialysis patients (3\%); 71 chronic renal patients $(60 \%)$ had received a blood transfusion.

The group of dialysis patients showed a TTVpositivity rate of $17 \%(21 / 118)$ when the method for detection of viremia proposed by Nishizawa et al. (1997) was used. In the second reaction, carried out as proposed by Devalle and Niel (2004), the rates of viremia detection increased from $17 \%(21 / 118)$ to $36 \%$ (43/118).

No statistically significant association was observed between the TTV frequency $(\mathrm{p}>0.05)$ and the patients' gender $(\mathrm{p}=0.33)$, age $(\mathrm{p}=0.44)$, time in dialysis $(\mathrm{p}=0.66)$, hepatitis $B$ virus $(p=0.62)$, or previous blood transfusions $(p=0.55)$.

Among the dialysis patients, genogroup 5 predominated (48\%), followed by genogroup $4(37 \%)$. No patient with genogroup 2 was found in this population. Nearly half (46\%) of the patients had only one of the circulating genogroups. No individual possessed four or five genogroups.

There was no statistically significant association ( $p>0.05$ ) between the genogroups identified and the gender, age of the patient, time in dialysis, presence of hepatitis B virus, or blood transfusion. Exceptionally, genogroup 4 showed a significant association with the patients' age and the dialysis time $(\mathrm{p}<0.05)$. In other words, genogroup 4 was most frequent among patients with a mean age of 64.5 and a mean dialysis period of 19.9 months.

Among the 50 renal-transplant patients, males predominated $(32 / 50 ; 64 \%)$, with a mean age of 44.0 years (SD 12.5). The mean post-transplant period was 99.4 months (SD 49.9 months).

The frequency of TTV in the renal transplant group was $10 \%(5 / 50)$ based on the presence of viral DNA. Use of the nested PCR technique for genogrouping, including all samples, resulted in a frequency of $54 \%$. Also, no signifi- cant association was found ( $\mathrm{p}>0.05)$ between positivity for TTV and the patients' gender $(\mathrm{p}=0.38)$, age $(\mathrm{p}=0.40)$ or post-transplant period $(\mathrm{p}=0.42)$.

Analyzing the frequency of each genogroup with respect to gender, age and post-transplant period yielded a significant association only for genogroup 3 , with respect to the mean time elapsed since the transplant $(\mathrm{p}<0.05)$. Genogroup 3 was most frequent among patients with a mean post-transplant period of 46.2 months.

Among renal-transplant patients, genogroup 5 was most prevalent (66\%), followed by genogroup $4(48 \%)$, and last by genogroup $2(7 \%)$. For the majority (51\%) of patients, only one genogroup was identified. Several patients showed the presence of several genogroups, but none showed the presence of all 5 .

\section{Discussion}

The PCR technique was used in this study to determine the frequency of entrainment of TTV DNA in samples obtained from the peripheral blood of patients on dialysis and recipients of renal transplants. The choice of primers used in the PCR reaction, to identify the presence of TTV, can strongly affect the level of detection of this microorganism in biological fluids, because certain segments of the viral DNA are less sensitive to the PCR technique (Devalle and Niel, 2004; Watanabe et al., 2005). Some investigators have also noted that the high rate of genetic mutation could make the PCR technique less sensitive for identifying this virus (Bendinelli et al., 2001).

The population of this study is similar to others in different parts of the world, and the results for frequency also vary within a wide range, possibly as a function of different methods used. Also, studies with nucleotide sequences from several samples revealed the existence of mutations in several animal species, creating the need for the virus to adapt to the new host (Biagini et al., 1999; Gallian et al., 1999). The use of more than one method, either for TTV identification or for genogrouping, proved to be essential because this is a highly mutable microorganism.

The TTV-positive prevalence of $36 \%$ observed among dialysis patients in this study is comparable to findings elsewhere of incidences from $9.3 \%$ (Kheradpezhouh et al., 2007) to 60.9 (Chan et al., 2000). We are aware of no other study of TTV occurrence among dialysis patients in Brazil. The transplant patients showed a higher prevalence of TTV (54\%) than the dialysis patients. This higher frequency could be explained by the immunosuppressive therapy that kidney-transplant patients receive (Burra et al., 2008). In Brazil, a similar TTV prevalence of 53.8\% was found in renal-transplant patients in Campinas (Yokosuka et al., 2000). However, few studies have investigated the prevalence of TTV in this group.

Research conducted in Italy showed a significant increase in TTV frequency after a liver transplantation procedure (Burra et al., 2008). This important information 
highlights the need for further studies to elucidate the possible association with the use of immunosuppressive drugs in recipients of renal transplants.

No significant association was found between TTV positivity and any of the epidemiological variables examined in this study (gender, time in dialysis, blood transfusions and the presence of hepatitis B), for either the dialysis or the renal-transplant patients. Other studies (Yokosuka et al., 2000; Shibuya et al., 2001; Martínez et al., 2000) have also found a lack of association with blood transfusions or with the presence of the hepatitis B virus. Although the parenteral route is considered the main means of transmission (Chan et al., 2000), these data suggest that other routes of viral propagation exist. The association between the presence of TTV and the possible etiology of hepatic diseases, a highly controversial subject, needs to be investigated before any causal relationship can be established (Chan et al., 2000; Watanabe et al., 2005; Pinto et al., 2007).

Genogroup 5 predominated among both the dialysis and transplant patients, and is the largest TTV genogroup circulating in the general Brazilian population (Costa, 2009). Genogroup 2 showed the lowest incidence and was found only among the renal-transplant patients; it is the least common group in Brazil (Devalle and Niel, 2004). The high frequency of genogroup 4 in both population samples (dialysis: $37 \%$; kidney transplant: $48 \%$ ) is notable. This finding contrasts with a study conducted in Rio de Janeiro with three different groups of patients (blood donors, patients with hepatitis B and HIV patients), where genogroup 4 was detected in only $17 \%$ of the subjects (Devalle and Niel, 2004). Also in the most recent survey conducted in five Brazilian states (Bahia, Espírito Santo, Minas Gerais, Rio de Janeiro and Rio Grande do Sul), genogroup 4 was present in only $21.5 \%$ of all samples analyzed (PinhoNascimento et al., 2011). Thus, further studies are needed, including a control group, to determine the general prevalence of each of the genogroups in Brazil.

In both patient populations, the majority of individuals showed only one genogroup, in agreement with other studies conducted in Brazil (Pinho-Nascimento et al., 2011; Vasconcelos et al., 2011). The identification of a single genogroup in most individuals may be favorable for the host's immune system, since the presence of several different genotypes could evade immune surveillance. Viruses that produce long-lasting infections may have coexisted with primates for millions of years, and their DNA shows a wide diversity of genetic variations (Bendinelli et al., 2001). Over the long run, the continuous TVV viremia could lead the immune system to adapt to the established viral infection (Costa et al., 2012). It was expected that a greater diversity of genogroups and also the presence of larger numbers of genogroups in the same patient would be found among renal-transplant patients, because of the immunosuppressive therapy that they receive.
The significant association of genogroup 3 with the mean age and mean time in dialysis, as well as the significant association of genogroup 4 with the mean post-transplant period deserve emphasis. The literature contains many studies on frequencies of genogroups, but no study has addressed the cause of this association. Possibly, stratification in younger age groups could clarify this association. There is also a need for more studies of the association of genogroups with epidemiological variables.

A high frequency of viremia was observed in both groups evaluated, in agreement with literature data. There was no statistically significant association between the TTV frequency and the variables gender, age, duration of treatment, blood transfusions or the presence of hepatitis B, in both groups. Further studies will be needed to clarify the significant association observed between genogroup 3 and the mean age and mean time in dialysis, as well as the significant association of genogroup 4 with the mean posttransplant period. The estimated frequency of viremia increased when a second method was used to determine the presence of the virus. Genogroup 5 was the most prevalent, and genogroup 2 occurred least frequently, in agreement with previous findings. In some patients, several genogroups were found. The results point to the need to determine the main routes of transmission of this agent, to aid in implementing barriers to its spread (Martins et al., 2008). Aspects such as the virus' biology and pathogenic capacity, and the clinical significance of TTV among dialysis and renal-transplant patients require further clarification.

\section{Acknowledgments}

The authors gratefully acknowledge the participation of the patients.

\section{References}

Amarante MFC, Kashima S, Covas DT (2007) TT virus (TTV) genotyping in blood donors and multiple transfused patients in Brazil. Virus Genes 35:503-509.

Bagaglio S, Sitia G, Prati D et al. (2002) Mother-to-child transmission of TT virus: sequence analysis of non-coding region of TT virus in infected mother-infant pairs. Arch Virol 147:803-812.

Barril G, González Parra E, Alcázar R et al. (2004) Guidelines on hemodialysis-associated viral infections. Nefrologia 24:4366.

Bendinelli M, Pistello M, Maggi F et al. (2001) Molecular properties, biology, and clinical implications of TT virus, a recently identified widespread infectious agent of humans. Clin Microbiol Rev 14:98-113.

Biagini P, Gallian P, Attoui H et al. (1999) Determination and phylogenetic analysis of partial sequences from TT virus isolates. J Gen Virol 80:419-424.

Biagini P, Todd D, Bendinelli M et al. (2004) Anellovirus. In: Fauquet CM, Mayo MA, Maniloff J et al. (eds) Virus Taxonomy. Eighth Report of the International Committee on Taxonomy of Viruses. Academic Press, London, pp 335-341. 
Burra P, Masier A, Boldrin C et al. (2008) Torque Teno Virus: any pathological role in liver transplanted patients? Transpl Int 21:972-979.

Campo N, Brizzolara R, Sinelli N et al. (2000) TT virus infection in haemodialysis patients. Nephrol Dial Transplant 15:1823-1826.

Chan YJ, Hsu YH, Chen MC et al. (2000) TT virus infection among hemodialysis patients at a medical center in Taiwan. J Microbiol Immunol Infect 33:14-18.

Costa MR, Costa IP, Devalle S et al. (2012). Prevalence and genetic diversity of torque teno virus in patients with systemic lupus erythematosus in a reference service in Mato Grosso do Sul. Rev Bras Reumatol 52:49-54.

Devalle S, Niel C (2004) Distribution of TT virus genomic groups 1-5 in Brazilian blood donors, HBV carriers, and HIV1-infected patients. J Med Virol 72:166-173.

Gallian P, Berland Y, Olmer M et al. (1999) TT virus infection in French hemodialysis patients: study of prevalence and risk factors. J Clin Microbiol 37:2538-2542.

Griffin JS, Plummer JD, Long SC (2008) Torque teno virus: an improved indicator for viral pathogens in drinking waters. Virol J 5:112.

Iso K, Suzuki Y, Takayama M (2001) Mother-to-infant transmission of TT virus in Japan. Int J Gynaecol Obstet 75:11-19.

Kheradpezhouh M, Taremi M, Gachkar L et al. (2007) Presence and significance of transfusion-transmitted virus infection in Iranian patients on maintenance hemodialysis. J Microbiol Immunol Infect 40:106-111.

Krekulova L, Rehak V, Killoran P et al. (2001) Genotypic distribution of TT virus (TTV) in a Czech population: evidence for sexual transmission of the virus. J Clin Virol 23:31-41.

Leary TP, Erker JC, Chalmers ML et al. (1999) Improved detection systems for TT virus reveal high prevalence in humans, non-human primates and farm animals. J Gen Virol 80:2115-2120.

Martínez NM, García F, García-Valdecasas J et al. (2000) Prevalence and viral persistence of TT virus in patients on hemodialysis. Eur J Clin Microbiol Infect Dis 19:878-880.

Martins KA, Tipple AFV, Souza ACS et al. (2008) Prevention and infection control of peripheral vascular access: the practice of nursing professionals. Ciênc Cuid Saúde 7:482-492.

Nishizawa T, Okamoto H, Konishi K et al. (1997) A novel DNA virus (TTV) associated with elevated transaminase levels in posttransfusion hepatitis of unknown etiology. Biochem Biophys Res Commun 241:92-97.
Okamoto H, Nishizawa T, Kato N et al. (1998) Molecular cloning and characterization of a novel DNA virus (TTV) associated with posttransfusion hepatitis of unknown etiology. Hepatol Res 10:1-16.

Oza VM, Jabbar AA, Hakobyan N et al. (2004) Transfusiontransmitted virus is not present in factor IX concentrates commonly used to treat haemophilia B. Haemophilia 10:732-734.

Peng YH, Nishizawa T, Takahashi M et al. (2002) Analysis of the entire genomes of thirteen TT virus variants classifiable into the fourth and fifth genetic groups, isolated from viremic infants. Arch Virol 147:21-41.

Pinho-Nascimento CA, Leite JP, Niel C et al. (2011) Torque teno virus in fecal samples of patients with gastroenteritis: prevalence, genogroups distribution, and viral load. J Med Virol 83:1107-1111.

Pinto WVM, Assis MFL, Lemos JAR (2007) Prevalence of the TTV in blood donors, in the metropolitan region of the Belém-Pará. Cad Saúde Colet 15:349-356.

Prescott LE, Simmonds P (1998) Global distribution of transfusion-transmitted virus. N Engl J Med 339:776-777.

Saláková M, Nemecek V, König J et al. (2004) Age-specific prevalence, transmission and phylogeny of TT virus in the Czech Republic. BMC Infect Dis 4:56.

Saláková M, Nemecek V, Tachezy R (2009) TTV and HPV co-infection in cervical smears of patients with cervical lesions. BMC Infect Dis 9:118.

Shibuya A, Satomichi A, Takeuchi A et al. (2001) Transfusion transmitted virus infection in patients on maintenance haemodialysis and in hospital workers. J Hosp Infect 47:277-281.

Vasconcelos HC, Menezes ME, Niel C (2001) TT virus infection in children and adults who visited a general hospital in the south of Brazil for routine procedure. Mem Inst Oswaldo Cruz 96:519-522.

Watanabe MAE, Miranda HC, Oliveira KB et al. (2005) Pathological and immunological aspects and molecular properties of TT virus. J Bras Patol Med Lab 41:223-228.

Yokosuka O, Ikeuchi T, Kanda T et al. (2000) The prevalence of TT virus infection in renal transplant recipients in Brazil. Transplantation 70:1194-1197.

Associate Editor: Maurício Lacerda Nogueira

All the content of the journal, except where otherwise noted, is licensed under a Creative Commons License CC BY-NC. 